\title{
Nursing care in the perioperative period for patients undergoing bariatric surgery
}

\author{
Cuidados de enfermagem no perioperatório de pacientes submetidos à cirurgia bariátrica
}

\author{
Atención de enfermería en el perioperatorio de pacientes sometidos a la cirugía bariátrica
}

\author{
Maria Beatriz Guimarães Ferreira ${ }^{1}$, Márcia Marques dos Santos Felix ${ }^{1}$, Cristina Maria Galvão ${ }^{2}$
}

This integrative review aimed to analyze the available evidence in the literature regarding nursing care in the perioperative period for patients who underwent bariatric surgery. The search for primary studies was carried out in the US National Library of Medicine National Institutes of Health, Cumulative Index to Nursing and Allied Health Literature and Latin American and Caribbean Health Sciences Literature databases. The sample was comprised of 11 primary studies, published between January 2002 and July 2013, and grouped in two categories. The main nursing care activities identified were: bed mobility, ambulation at 12 hours, thromboembolic prophylaxis using compression devices, antibiotic prophylaxis, care for surgical drains, catheters and wound dressings, and guidance for patients regarding pre and postoperative preparation. The difficulties experienced by nurses and the team in the care provided were also discussed.

Descriptors: Bariatric Surgery; Perioperative Nursing; Nursing Care.

Objetivou-se analisar evidências disponíveis na literatura sobre os cuidados de Enfermagem no perioperatório de pacientes submetidos à cirurgia bariátrica. Para tanto, conduziu-se revisão integrativa. A busca dos estudos primários foi realizada nas bases de dados US National Library of Medicine National Institutes of Health, Cumulative Index to Nursing and Allied Health Literature e Literatura Latino-Americana e do Caribe em Ciências da Saúde. A amostra foi composta de 11 estudos primários, publicados entre janeiro de 2002 e julho de 2013, agrupados em duas categorias. Os principais cuidados identificados foram mobilidade no leito, deambulação em 12 horas, profilaxia tromboembolítica por meio de dispositivos de compressão, antibioticoprofilaxia, cuidados com drenos, cateteres e curativos e ensino do paciente sobre preparo pré e pós-operatório. As dificuldades vivenciadas pelo enfermeiro e pela equipe na assistência prestada também foram discutidas.

Descritores: Cirurgia Bariátrica; Enfermagem Perioperatória; Cuidados de Enfermagem.

El objetivo fue analizar evidencias disponibles en la literatura acerca de la atención de enfermería en el perioperatorio de pacientes sometidos a cirugía bariátrica. Para esto, se realizó revisión integradora. La búsqueda de estudios primarios se realizó en las bases US National Library of Medicine National Institutes of Health, Cumulative Index to Nursing and Allied Health Literature y Literatura Latino Americana y del Caribe en Ciencias de la Salud. La muestra consistió de 11 estudios primarios, publicados entre enero de 2002 y julio de 2013, agrupados en dos categorías. Las principales acciones de atención de enfermería identificadas fueron movilidad en el lecho, deambulación en 12 horas, profilaxis tromboembólica utilizándose dispositivos de compresión, profilaxis antibiótica, atención con drenaje, catéteres y vendajes, enseñanza del paciente sobre preparo pre y postoperatorio. Las dificultades vivenciadas por enfermeros y equipo en la atención ofrecida también se discutieron.

Descriptores: Cirurgía Bariátrica; Enfermería Perioperatoria; Atención de Enfermería.

\footnotetext{
${ }^{1}$ Universidade Federal do Triângulo Mineiro. Uberaba, MG, Brazil.

${ }^{2}$ Escola de Enfermagem de Ribeirão Preto, Universidade de São Paulo. Ribeirão Preto, SP, Brazil.

Corresponding author: Cristina Maria Galvão

Av. Bandeirantes, 3900 Campus Universitário - Monte Alegre. CEP: 14040-902. Ribeirão Preto, SP, Brazil. E-mail: crisgalv@eerp.usp.br
} 


\section{Introduction}

Because of its high prevalence, obesity is considered a public health problem, in addition to being characterized as a clinical-epidemiological occurrence with high mortality, due to the comorbidities associated with it, such as diabetes mellitus, dyslipidemia, sleep apnea, and cardiac and neurological diseases ${ }^{(1)}$.

It is a complex morbidity determined by genetic, social, economic and cultural factors, as well as inappropriate eating habits. It is coming to be seen as a chronic illness because of its social, clinical and physiological repercussions which affect individuals of any age or social class ${ }^{(2)}$. As a result, it is a growing challenge for individual health, organizations and health professionals, as it is mainly attributed to a diet rich in high-energy foods and fats, and to a sedentary lifestyle ${ }^{(1)}$.

For the World Health Organization, obesity is classified by Body Mass Index over $30 \mathrm{~kg} / \mathrm{m}^{2}$. This is calculated by body weight, in kilograms, divided by the square of the height in square meters (Body Mass Index $=\mathrm{kg} / \mathrm{h}^{2}$ ). The severity of the obesity is divided by Body Mass Index into grade I $\left(30-34.9 \mathrm{~kg} / \mathrm{m}^{2}\right)$, grade II $\left(35-39.9 \mathrm{~kg} / \mathrm{m}^{2}\right)$ and grade III - or morbid obesity $\left(\geq 40 \mathrm{~kg} / \mathrm{m}^{2}\right)^{(3)}$.

Bariatric surgery is the most efficacious treatment for adults with morbid obesity, resulting, in a short period, in weight loss which can reach $60 \%$ of the excess body weight, as well as improvement for resolution of comorbidities, increase in quality of life, and greater survival ${ }^{(4)}$. This surgery is indicated for adults with Body Mass Index $\geq 35 \mathrm{~kg} / \mathrm{m}^{2}$ with one or more significant obesity-related comorbidities. Undertaken using different techniques, bariatric surgery alters the normal digestive process, resulting in clinical and functional benefits - in particular, reduction in weight, morbidity and mortality ${ }^{(5)}$.

Bariatric surgery is responsible for a series of physical and psychological changes experienced by the patients undergoing this procedure. Advances in surgery and anesthesia, along with demographic changes and increasing levels of patient obesity, have increased the need for efficacious and vigilant Nursing care $^{(6)}$. The individual's expectations in relation to the treatment, the hospitalization, and the quality of the care are a factor which can influence his recovery ${ }^{(7)}$.

The multidisciplinary team working in the perioperative care for these patients aims to prevent or to treat possible complications, and to offer care and support, initiating activities prior to the bariatric surgery, and extending these for a minimum of five years in the postoperative period. As a member of the multidisciplinary team, the nurse must ensure care and health education, with a view to preventing complications, determining well-being, and helping the patient to adapt to the new way of living. It is expected that this professional should be able to appropriately identify the problems of the patient undergoing bariatric surgery, related to the surgical risks and the comorbidities associated with the clinical condition of obesity, and be able to implement appropriate solutions ${ }^{(8)}$.

In the light of the above, this study's importance lies in the fact that it summarizes the knowledge relating to the nursing care in the perioperative period for patients undergoing bariatric surgery, offering support for guiding the nurse in the planning and implementation of safe, quality care, as well as promoting reflection and discussion on the clinical practice, with a view to constructing a nursing care plan grounded in scientific knowledge. Thus, the present study aims to analyze evidence available in the literature regarding the nursing care in the perioperative period for patients undergoing bariatric surgery.

\section{Method}

As an integrative review was selected as the review method for achieving the study objective, the following stages were conducted: the elaboration of the research question; sampling, or search in the literature composed of primary studies; data extraction; evaluation of the primary studies included in the review; analysis and summary of the results of the re- 
view, and presentation of the review. Primary studies are the original investigations ${ }^{(9)}$.

The guiding question for the integrative review was: What is the evidence available in the literature regarding the nursing care in the perioperative period provided to patients undergoing bariatric surgery?

The search for the primary studies was undertaken in the following databases: US National Library of Medicine National Institutes of Health (PubMed), Cumulative Index to Nursing and Allied Health Literature (CINAHL) and the Latin-American and Caribbean Health Sciences Literature (LILACS). To this end, the following Medical Subject Headings controlled descriptors were used: Bariatric Surgery; Gastroplasty; Preoperative period; Intraoperative period; Postoperative period; Perioperative period; Nursing; Obesity, Morbid; Perioperative Nursing; CINAHL Headings: Bariatric Surgery; Gastroplasty; Preoperative period; Intraoperative period; Postoperative period; Perioperative Nursing; Nursing Interventions; and Obesity, Morbid: as well as the following Health Science Descriptors in Portuguese: Cirurgia Bariátrica; Gastroplastia; Período PréOperatório; Período Intra-Operatório; Período PósOperatório; Período Perioperatório; Enfermagem; Enfermagem perioperatória; and Obesidade Mórbida. Another strategy adopted was the manual search through the bibliographic references of the primary studies selected. With the aim of ensuring a broad search, the controlled descriptors were combined in different ways. Figure 1 presents only the combinations undertaken which made possible the identification of primary studies included in the integrative review.

The inclusion criteria for the primary studies, outlined for the integrative review, were studies which describe the nursing care provided to patients undergoing bariatric surgery in the perioperative period; published in English, Portuguese or Spanish, in the period January 2002 - July 2013. The narrative reviews of the literature/traditional reviews, methods of reviews (for example, systematic reviews), editorials or letters of response were excluded.
The search for primary studies in the databases selected took place in September 2013, and was undertaken by two reviewers independently (Figure 2).

After the title and abstract of all the eligible primary studies had been read, and in accordance with the integrative review's guiding question and selection criteria, 12 studies were selected, and were read exhaustively in full. The stages described were undertaken by two reviewers independently.

The extraction of data from the primary studies selected was undertaken using a data collection instrument proposed by the author of a nursing study ${ }^{(10)}$. The instrument in question was submitted for face and content validation. This is made up of five items, namely: identification of the study; the institution where the study was based; type of scientific review; methodological characteristics of the study, and the evaluation of the methodological rigor.

During the data extraction, it was observed that one study from the CINAHL database did not describe the topic of interest. As a result, the integrative review's sample was made up of 11 primary studies, with four from the PubMed database, two from CINAHL, one from LILACS, and four resulting from the manual search.

The evaluation of the types of studies selected was undertaken based in the concepts of academics of scientific methodology ${ }^{(11)}$. These academics classify the studies into two methodological approaches: quantitative and qualitative. In the first, the research designs are divided into experimental, quasiexperimental, and non-experimental. In the second methodological approach, the authors present the different types of qualitative research, for example, ethnography, phenomenology, and Grounded Theory.

The analysis of the results evidenced was undertaken descriptively, with the presentation of a summary of each study included in the integrative review, as well as comparisons between these, emphasizing differences and similarities. 


\begin{tabular}{|l|l|l|l|}
\hline Database & \multicolumn{3}{|c|}{ Combinations } \\
\hline \multirow{3}{*}{ PubMed } & $\begin{array}{l}\text { Bariatric Surgery } \\
\text { OR Gastroplasty AND Preoperative } \\
\text { Period }\end{array}$ & $\begin{array}{l}\text { Bariatric Surgery } \\
\text { OR Gastroplasty AND Postoperative } \\
\text { Period }\end{array}$ & $\begin{array}{l}\text { Bariatric Surgery } \\
\text { OR Gastroplasty AND } \\
\text { Perioperative Nursing }\end{array}$ \\
\hline CINAHL & $\begin{array}{l}\text { Bariatric Surgery } \\
\text { OR Gastroplasty AND Postoperative } \\
\text { Period }\end{array}$ & $\begin{array}{l}\text { Bariatric Surgery } \\
\text { OR Gastroplasty AND Nursing }\end{array}$ & \\
\hline LILACS & Cirurgia Bariátria & & \\
\hline
\end{tabular}

Figure 1 - Combinations made which allowed the identification of primary studies included in the integrative review

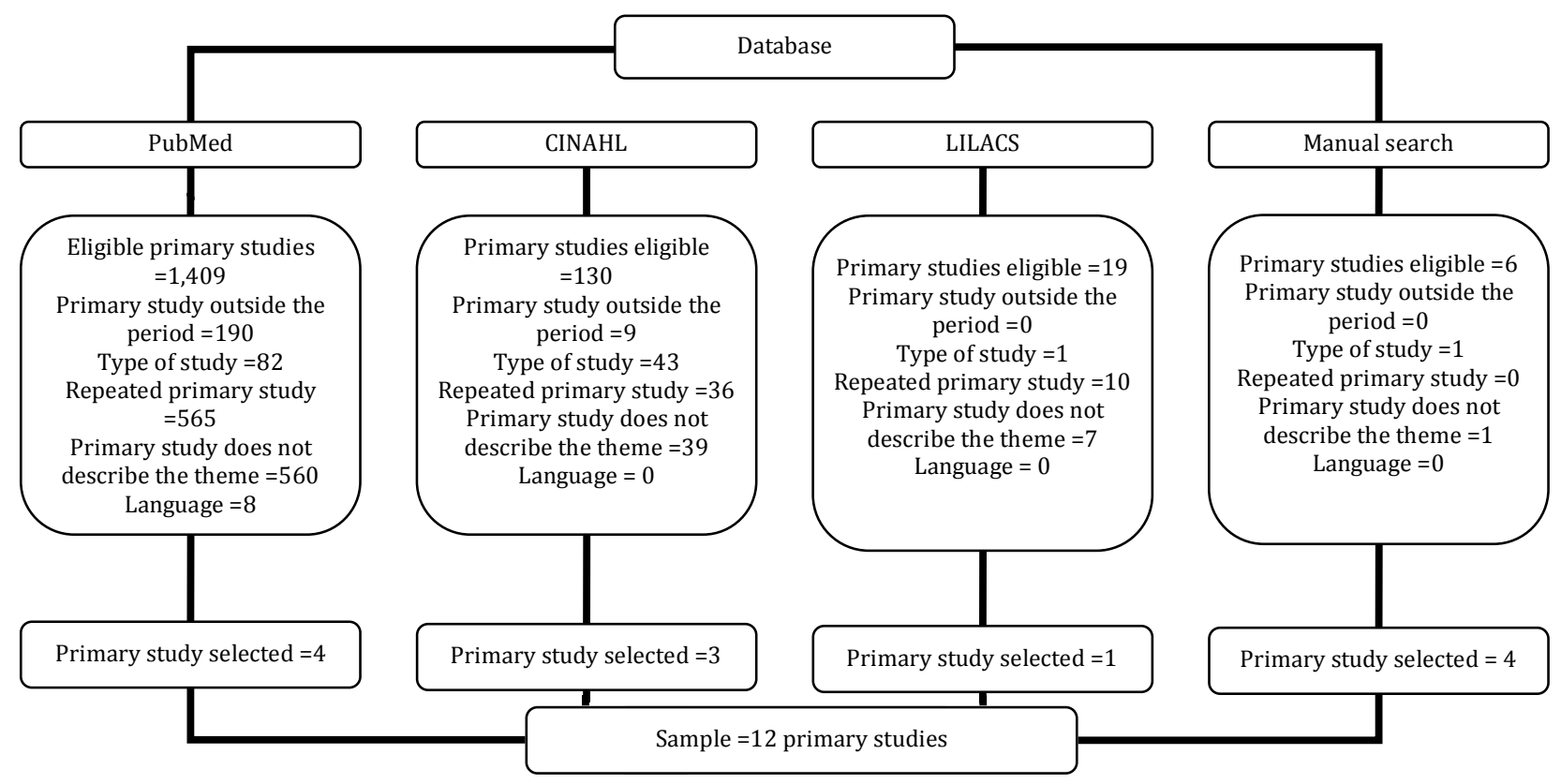

Figure 2 - Flow chart for the selection of the primary studies eligible, and reasons for exclusion

\section{Results}

Of the 11 primary studies included in the present study, eight were published in English. There was variety in relation to the periodicals, with more than one study published in Bariatric Nursing and Surgical Patient Care ( $\mathrm{n}=2$ ) and Surgery for Obesity and Related Diseases ( $\mathrm{n}=2$ ). In relation to the Brazilian periodicals, one study was published in each of the following journals: Revista Brasileira de Enfermagem, Acta Paulista de Enfermagem and Revista de Enfermagem da Universidade Federal de Pernambuco.
The primary studies included in the integrative review were grouped in two categories, namely: Nursing care in the perioperative period; and Human and material resources, equipment, and physical structure. Figure 3 presents the general characterization of the primary studies, with studies one - eight being grouped in the first category, and studies nine - 11 in the second. 


\begin{tabular}{|l|l|l|}
\hline Title & Year & \multicolumn{1}{|c|}{ Type of study } \\
\hline 1. Body lift: an account of 200 consecutive cases in the massive weight loss patient & 2006 & Retrospective correlational study \\
\hline $\begin{array}{l}\text { 2. Nursing process based in Orem's Self-Care Theory for a patient who underwent } \\
\text { bariatric surgery }\end{array}$ & 2009 & $\begin{array}{l}\text { Case study (qualitative methodological } \\
\text { approach) }\end{array}$ \\
\hline $\begin{array}{l}\text { 3. Prospective, randomized, pilot study evaluating the effect of ice chips } \\
\text { administration versus none on the bitterness of crushed medications in } \\
\text { postoperative bariatric patients }\end{array}$ & 2011 & Randomized clinical trial \\
\hline \begin{tabular}{l} 
4. Quality indicators in bariatric surgery: improving quality of care \\
\hline 5. Can nurses impact patient outcomes using a patient-centered care model?
\end{tabular} & 2006 & Methodological study \\
\hline 6. Effect of patient-centered care on patient satisfaction and quality of care & 2008 & Randomized clinical trial \\
\hline $\begin{array}{l}\text { 7. Protocol for nursing care for the patient in the pre and postoperative period } \\
\text { for bariatric surgery }\end{array}$ & 2012 & Methodological study \\
\hline 8. Bariatric surgery: patient incision care and discharge concerns & 2006 & Prospective transversal study \\
\hline $\begin{array}{l}\text { 9. Care for the morbidly obese patient undergoing bariatric surgery: the nurse's } \\
\text { difficulties }\end{array}$ & 2009 & $\begin{array}{l}\text { Exploratory-descriptive (quantitative } \\
\text { methodological approach) }\end{array}$ \\
\hline $\begin{array}{l}\text { 10. Challenges that nurses face in caring for morbidly obese patients in the acute } \\
\text { care setting }\end{array}$ & 2005 & $\begin{array}{l}\text { Descriptive study (qualitative methodo- } \\
\text { logical approach) }\end{array}$ \\
\hline $\begin{array}{l}\text { 11. Nurse staffing requirements for care of morbidly obese patients in the acute } \\
\text { care setting }\end{array}$ & 2006 & $\begin{array}{l}\text { Descriptive study (quantitative methodo- } \\
\text { logical approach) }\end{array}$ \\
\hline
\end{tabular}

Figure 3 - Characterization of the primary studies included (title, year of publication, and type of study)

Below, this article presents a summary of each study grouped in the category of Nursing care in the perioperative period. Study 1 aimed to analyze the results of a surgical technique (Body Lift), the care, and the most frequent complications. The sample consisted of 200 patients (166 women and 34 men). The results evidenced an appropriate surgical technique, emphasizing that the selection of the patient and his education are crucial aspects for achieving success in the treatment. The main care mentioned was: use of the Foley catheter or sequential compression device, being restricted to bed until the day following the surgery, ambulation following tolerance of the sitting position, drain care, and the administration of antibiotics. As the most frequent complications, the results indicated dehiscence, seroma, skin necrosis, deep vein thrombosis, bleeding, and pulmonary embolism ${ }^{(12)}$.

The study objective was to apply the Nursing Process in the case of a patient undergoing bariatric surgery. The Nursing Diagnoses were identified using the taxonomy of the North American Nursing
Diagnosis Association and the planning of the care was based in Orem's Self-Care Theory. Among the results, the care necessary for the surgical patient included promoting mobility in the bed and ambulation, minimizing the risks for infections, caring for dressings, drains and catheters, respiratory exercises and pulmonary auscultation, administration of antibiotics, analgesics and antiemetics, indwelling urinary catheterization, monitoring, promotion of sleep and relaxation, and guidance relating to the surgical procedure, possible complications, self-care steps and care in the home (surgical wound and skin). As complications mentioned, there were infection in the wound, dehiscence, fistulas, dumping syndrome, pneumopathies, thrombophlebitis and deep vein thrombosis ${ }^{(13)}$.

The research design of study 3 was a clinical trial, whose objective was to evaluate whether the administration of pieces of ice on the patient's tongue in the postoperative period before and after the administration of medicines resulted in the perception of improvement of the sense of taste and/or bitter 
taste. The sample was made up of 100 subjects (control group $=50$ and intervention group $=50$ ) . The intervention tested was undertaken before and after the administration of medications, in which the patients placed $15 \mathrm{ml}$ of crushed ice on their tongues and left it there for one minute. The results evidenced that the intervention tested promoted improvement in flavor and reduction of the bitter taste, especially for analgesics, antihypertensives, and antidepressants ${ }^{(14)}$.

The aim of study 4 was to develop quality indicators for defining a consensus of the care practices for the patient undergoing bariatric surgery. The results indicated 50 valid indicators, divided into five domains: criteria for the training of surgeons, preoperative evaluation, intraoperative technique, intensive care in the postoperative period, and care in the postoperative period and long-term. The nursing care actions identified in the results as quality indicators were: identification of complications, assistance in ambulation at 12 hours, prophylaxis of deep vein thrombosis with mechanical devices and subcutaneous heparin, antibiotic therapy, administration of fluids, appropriate position on the operating table, follow-up visits the adoption of the clinical protocol, guidance in relation to the surgical process, signing of the terms of informed consent in the preoperative assessment, instructions relating to diet, changes in medications, and signs of complications in the postoperative period ${ }^{(15)}$.

In study 5, the researchers investigated whether the nurses adopting the Patient-Centered Model of Care in the practice could produce an effect on patient satisfaction, the perception of the nursing care, and the quality of the results of the care given. The instruments used were the Schmidt Perception of Nursing Care Survey and the Baker \& Taylor Measurement Scale, as well as a search in the medical records for identifying adverse events. The nurses who use the Model in question provided care centered on the patient's needs. The patients were to receive gastric bypass surgery (control group $=58$ and intervention group $=58$ ). There were no statistically significant differences between the groups in relation to the instruments applied and the complications, namely: length of stay in hospital, infection or postoperative adhesions, renal failure, gastric hemorrhage and atrial fibrillation. However, in relation to the qualitative results, the intervention group (patients who were assisted using the Patient-Centered Model of Care) did not present preoperative worry, and were shown to be more open and communicative. In relation to health education, the following aspects were indicated as relevant: the inclusion of the caregiver in the planning and implementation of the care, educational activities in the presurgical process for identifying objectives, concerns, expectations and fears relating to the hospitalization, minimizing anxiety and managing comorbidities, and - in the postoperative period - for improving the patient's level of satisfaction and pain management ${ }^{(16)}$.

In study 6, the authors also investigated the Patient-Centered Model of Care, with the objective of ascertaining the effect of this Model on patient satisfaction, perception of the nursing care, and the quality of the care. The subjects who participated (18 in the intervention group and 18 in the control group) were patients undergoing gastric bypass surgery. The results demonstrated that the patients' satisfaction and the quality of the services obtained higher classifications in the intervention group (patients who were assisted using the Model in question). In relation to teaching the patient, information on pain control and the procedures must be provided in the preoperative period, with a view to the success of the surgery and - in the postoperative period - the educational activities must be directed towards preparation for discharge from hospital and transition to the home ${ }^{(17)}$.

The objective of study 7 - which had Orem's SelfCare Theory as its theoretical framework - was the construction of a nursing care protocol for the patients in the pre and postoperative period for bariatric surgery. The undertaking of the study allowed the indication of indicators for the therapeutic demand 
for self-care; and the determination, development and setting up of nursing systems for the self-care deficits, defining the roles of the nurse. The protocol elaborated presented nursing actions for the following Nursing Diagnoses: inefficient respiratory pattern, risk for fluid volume deficit, imbalanced nutrition more than body requirements, diarrhea and constipation, sedentary lifestyle, disturbed sleep pattern, impaired social interaction, inadequate knowledge regarding complications related to obesity and bariatric surgery, disorder in body image, and inefficient maintenance of health ${ }^{(18)}$.

In study 8, the sample was made up of 31 subjects undergoing gastric bypass surgery, and the study aimed to assess the patients' knowledge regarding the care for the incision and aspects of discharge from hospital. The participants answered questionnaires which included demographic information, data on knowledge referent to care for the incision, fears, and aspects of the discharge from hospital (scales). The five aspects related to discharge from hospital mentioned most frequently were: problems with the intestines, pain in the incision, complications of the wound, identification of infection, and limitation of activities. The results evidenced that those patients who received little information regarding care for the incision had a higher degree of fear, and that those who reported severe pain presented greater concern regarding discharge from hospital ${ }^{(19)}$.

The second category (human and material resources, equipment, and physical structure) included three primary studies. Study 9 aimed to identify the difficulties of nurses ( $n=70$ ) of the surgical center in assisting patients with obesity. Among the difficulties listed, the professionals indicated the inadequate size of the operating room; the absence of a special transfer trolley, surgical table, accessories, adjustable boot-type leg rests, material for anesthesia and safety belts; a reduced number of personnel for transferring patients, mobilizing, transport, and positioning the patient, as well as difficulty in undertaking the technique of urinary catheterization.
In conclusion, difficulties were related to the physical area, to the materials and equipment, and to the assistance provided ${ }^{(20)}$.

Study 10 focused on the perception of the nurses $(n=17)$ regarding the challenges in caring for the patient with obesity (qualitative research, using the focus group technique). The challenges of providing the nursing care reported were the absence of a specific system for classifying patients and the specialized team, the workload, the need for more staff, the patients' psycho-social needs, the team's difficulties for mobilizing and assisting/undertaking basic daily activities, shortages of specific equipment and materials such as beds, chairs, clothes, bedpans, pressure cuffs and the size of the rooms, as well as the personal safety of the nursing staff and the patients ${ }^{(21)}$. The objective of study 11 was to investigate the nursing staff's needs in caring for the patient with obesity and issues of safety. Two investigators collected data regarding the nursing care, through the observation of 30 patients. The authors analyzed 59 nursing activities. The activities which needed the most time and number of members of the nursing team were, consecutively, assisting with ambulation, giving baths, helping the patient to sit, and positioning the patient in the bed. Incidents referent to the security of the professionals and the patients were identified during the care provided (for example, in transferring the patient from the transfer trolley to the bed, and change of position) $)^{(22)}$.

\section{Discussion}

The primary studies included in the first category mainly investigated the nursing care provided to the patients undergoing bariatric surgery, the model of care applied in the practice, and aspects relevant to the education of the patient in the pre and postoperative period ${ }^{(12-19)}$.

In the studies selected for undertaking the integrative review, among the nursing care actions for bariatric surgery, the following standout: mobility 
in the bed, ambulation at 12 hours, thromboembolic prophylaxis forma through the use of compression devices, antibiotic prophylaxis, and care for drains, catheters and dressings ${ }^{(12-13,15)}$.

Another publication was found in the literature relating to the integrative review's topic of interest, which was undertaken with the objective of identifying the Nursing Diagnoses of the cardiovascular and pulmonary response classes in patients undergoing bariatric surgery, the following diagnoses being identified with the greatest frequency: risk of reduced cardiac tissue perfusion, ineffective peripheral tissue perfusion, reduced cardiac output, intolerance to activity and risk of ineffective renal perfusion. The diagnoses identified may support the elaboration of specific care plans for this clientele's needs ${ }^{(23)}$.

In the present integrative review, the authors of two primary studies ${ }^{(16-17)}$ applied the PatientCentered Model of Care in clinical practice. The results demonstrated improvement in the patients' level of satisfaction and in the quality of the care when the nurse provides care with emphasis on the clientele's individual needs, also geared towards health education.

The importance of teaching in the preparation of the patient in the pre and postoperative period was also an aspect discussed in the studies selected. Among the topics listed, the following standout: information on necessary care actions and procedures, clearing up doubts, preparation for discharge, teaching the caregiver, and care in the home ${ }^{(18-19)}$. The teaching is also a priority aspect in another publication in the literature on bariatric surgery. The preoperative period is when the nurse must ensure that the patient receives the necessary information and understands the entire process of hospitalization; in the postoperative period, the family's involvement is fundamental for assisting in the patient's transition home, as well as in care provided in the home ${ }^{(8)}$.

In the second category, the primary studies' results indicated that the nurse and team experience difficulties in providing nursing care to the patient with obesity. The difficulties identified with the greatest frequency were the special needs for equipment, materials and furniture, numbers of staff, the time necessary for undertaking the nursing interventions, and the infrastructure of the places where care was provided. The need for the appropriate quantity of human resources and the use of specific material resources are crucial conditions for promoting the comfort and safety of patients with morbid obesity ${ }^{(20-22)}$.

An integrative review conducted with the objective of analyzing knowledge production regarding clinical advances in the needs of patients receiving bariatric surgery in the intraoperative period was identified in the literature, with 12 primary studies being included. The results evidenced indicated that the needs have already been described well in relation to the appropriate dimensions of the operating room, a surgical table which favors positioning in the supine position and transference to the transfer trolley, special leg rests, safety belts, sphygmomanometers in extra-large sizes, materials for anesthesia, special techniques for urinary catheterization or procedures undertaken by three people, and the compression devices. The authors understand that patient safety also encompasses the emotional dimension - and this aspect was little addressed ${ }^{(24)}$. This result is similar to the data found in the present review.

\section{Conclusion}

Patients undergoing bariatric surgery need differentiated nursing care in the perioperative period. The nursing care actions identified in the present review mainly cover aspects referent to mobility and ambulation, thromboembolic prophylaxis, drug therapy, care for drains, dressings and catheters, education of the patient in the pre and postoperative period, and individualized actions which meet the patients' real needs. In addition to this, in order to provide the nursing care with quality and safety, it is necessary to overcome challenges relating to the 
appropriate quantity of human resources, as well as the provision by the health institution of special equipment, materials, and appropriate physical structure.

The construction of a care protocol based on evidence arising from results of research can be a tool which assists the nurse's decision-making in clinical practice. This protocol must include the specific care actions which cover the physical and emotional needs of the patient undergoing bariatric surgery, aspects of safety, preparation for discharge from hospital, and care in the home.

Emphasis is placed on the scarcity of studies on the issue in question, and the need for holding further studies providing support for the improvement of the current standards of nursing care, permitting better results for the patient and health institution.

\section{Acknowledgments}

The authors express their gratitude to the National Council for Scientific and Technological Development, for the financial support for the undertaking of this work, through a Research Productivity grant.

\section{Collaborations}

Ferreira MBG and Felix MMS contributed to the conception of the work, data collection, analysis and interpretation of data, editing of the article, and approval of the final version to be published. Galvão CM contributed to the conception of the work, analysis and interpretation of the data, editing of the article and approval of the final version to be published.

\section{References}

1. Karim MA, Ahmed J, Arneil C, Ali A. Utilization of hospital services by obese patients before and after bariatric surgery. Surg Today. 2013; 43(10):1129-33.
2. Costa ACC, Ivo ML, Cantero WB, Tognini JRF. Obesity in candidates for bariatric surgery. Acta Paul Enferm. 2009; 22(1):55-9.

3. Tavares TB, Nunes SM, Santos MO. Obesidade e qualidade de vida: revisão de literatura. Rev Med Minas Gerais. 2010; 3(20):359-66.

4. Conason A, Teixeira J, Hsu CH, Puma L, Knafo D, Geliebter A. Substance use following bariatric weight loss surgery. JAMA Surg. 2013; 148(2):14550 .

5. Marzen-Groller KD, Cheever KH. Facilitating students'competence in caring for the bariatric surgical patient: the case study approach. Bariatr Nurs Surg Patient Care. 2010; 5(2):117-25.

6. Mulligan AT, Mcnamara AM, Boulton HW, Trainor LS, Raiano C, Mullen A. Best practice updates for nursing care in weight loss surgery. Obesity. 2009; 17(5):895-900.

7. Razera APR, Braga EM. The importance of communication during the postoperative recovery period. Rev Esc Enferm USP. 2011; 45(3):632-7.

8. Hawn K, Doane A. Management of the surgical weight loss patient. View Point. 2011; 33(2):1,6-9.

9. Galvão CM, Mendes KDS, Silveira RCCP. Revisão integrativa: método de revisão para sintetizar as evidências disponíveis na literatura. In: Brevidelli MM, Sertório SCM. Trabalho de conclusão de curso: guia prático para docentes e alunos da área da saúde. São Paulo: Iátrica; 2010. p.105-26.

10. Ursi ES, Galvão CM. Prevenção de lesões de pele no perioperatório: revisão integrativa da literatura. Rev Latino-Am Enfermagem. 2006; 14(1):124-31.

11. Polit DF, Beck CT. Fundamentos de pesquisa em enfermagem: avaliação de evidências para a prática de enfermagem. 7aㅡ ed. Porto Alegre: Artmed; 2011.

12. Nemerofsky RB, Oliak D, Capella JF. Body lift: an account of 200 consecutive cases in the massive weight loss patient. Plast Reconstr Surg. 2006; 117(2):414-30.

13. Felix LG, Nóbrega MML, Soares MJGO. Processo de enfermagem fundamentado na Teoria do autocuidado de Orem a um paciente submetido à cirurgia bariátrica. Rev Enferm UFPE on line. [periódico na Internet] 2009 [citado Jun 
13];3(4):814-22. Disponível em: http://www. revistaufpe.br/revistaenfermagem.

14. Suchicital LG, Gujral H, Speroni KG, Eldridge D, Atherton M. Prospective, randomized, pilot study evaluating the effect of ice chips administration versus none on the bitterness of crushed medications in postoperative bariatric patients. Bariatr Nurs Surg Patient Care. 2011; 6(1):15-20.

15. Maggard MA, McGory ML, Shekelle PG, Ko CY. Quality indicators in bariatric surgery: improving quality of care. Surg Obes Relat Dis. 2006; 2(4):423-30.

16. Wolf D, Lehman L, Quinlin R, Rosenzweig M, Friede S, Zullo T, et al. Can nurses impact patient outcomes using a patient-centered care model? J Nurs Adm. 2008; 38(12):532-40.

17. Wolf DM, Lehman L, Quinlin R, Zullo T, Hoffman L. Effect of patient-centered care on patient satisfaction and quality of care. J Nurs Care Qual. 2008; 23(4):316-21.

18. Felix LG, Soares MJGO, Nóbrega MML. Protocolo de assistência de enfermagem ao paciente em pré e pós-operatório de cirurgia bariátrica. Rev Bras Enferm. 2012; 65(1):83-91.
19. Pieper B, Sieggreen M, Nordstrom C, Kulwicki P, Freeland B, Palleschi MT, et al. Bariatric surgery: patient incision care and discharge concerns. Ostomy Wound Manage. 2006; 52(6):48-61.

20. Tanaka DS, Peniche ACG. Assistência ao paciente obeso mórbido submetido à cirurgia bariátrica: dificuldades do enfermeiro. Acta Paul Enferm. 2009; 22(5):618-23.

21. Drake D, Dutton K, Engelke M, McAuliffe M, Rose MA. Challenges that nurses face in caring for morbidly obese patients in the acute care setting. Surg Obes Relat Dis. 2005; 1(5):462-6.

22. Rose MA, Baker G, Drake DJ, Engelke M, McAuliffe $M$, Pokorny $M$, et al. Nurse staffing requirements for care of morbidly obese patients in the acute care setting. Bariatr Nurs Surg Patient Care. 2006; 1(2):115-21.

23. Moreira RAN, Barros LM, Rodrigues AB, Caetano JÁ. Nursing diagnoses, interventions and outcomes in the bariatric surgery postoperative care. Rev Rene. 2013; 14(5):960-70.

24. Rodrigues RTF, Lacerda RA, Leite RB, Graziano $\mathrm{KU}$, Padilha KG. Intraoperative nursing in bariatric surgery: integrative review. Rev Esc Enferm USP. 2012; 46(n. esp.):138-47. 